\title{
The inquiry of the development and utilization of the ideological and
}

\author{
political lesson
}

\section{ZhaoHongxiang}

\author{
School of economics and management, Shenyang University of Aeronautics and Astronautics
}

Keywords: The ideological and political; Curriculum resources; Development and utilization.

\begin{abstract}
The development and utilization of curriculum resources is driving China's education reform levels in all schools have produced results. In this paper, we tend to find the problems of the development and utilization of ideological and political lesson curriculum resources on the basis of theoretical analysis existing in the process of curriculum resources development and utilization, to reveal the reasons and puts forward the measures and tries to promote the ideological and political course resources development and utilization to provide referential experience and enrich the ideological and political lesson teaching efficiency.
\end{abstract}

\section{Connotation and characteristics of the ideological and political lesson curriculum resources}

Ideological and political lesson guide students to build good ideology, morality, psychological quality and other major responsibilities. Ideological and political lesson throughout the economy, politics, culture, philosophy, four basic aspects to guide students in study and social practice to understand political theory and economic policy, cultural diversity to grasp the method of philosophy to improve their ability of thinking and to improve the ability to participate in social life, set up the correct world outlook, the outlook on life, values, and lay solid foundations for the all round development of students.

The curriculum is the curriculum design, implementation, and evaluation of curriculum development process; you can use the sum of all the human, materials and natural resources. Along with the deepening of the reform process of the new curriculum, more and more teachers feel that implementation of new courses needs to have enough resources to support, especially in politics, without the support of curriculum resources; class politics will lose its vitality and become empty talk and mechanical knowledge. For a long time, due to the level of economic development, underdeveloped level, education curriculum concepts, development of management system of the restriction make curriculum shortages become a common phenomenon in China, and it cannot meet the needs of new curriculum implementation, therefore, the study of development and utilization of curriculum resources would become an important driver of reform. The use of ideological and political courses in the exploitation and utilization of curriculum resources can increase flexibility, selective, and make ideological and political course more appropriate to different parts of the economy, culture as well as the students ' individual development needs, it has the advantage of break the situation of textbook-takes to achieve diversification of the curriculum and teaching materials. In this sense, implementation status of ideological and political courses, which is depend on the richness of the politics course resources, and the level of exploitation and utilization of 
curriculum resources, it has significance to the study of utilization the curriculum resources in ideological.

\section{The characteristics of the ideological and political lesson curriculum resources.}

According to the nature and content of ideological and political course, the development and utilization of course resources has the characteristics of the following aspects: first, the ideological education. In the growth stage of college students' vigorous, dares to practice, but it has the lack of self-control and easy one-sided when seeing a problem. In the process of the formation for the students to correct world outlook, the outlook on life and the values, political teachers' guidance is particularly important. In the process of teaching, the teacher wants to accelerate the development and utilization of curriculum resources, play to the ideological and political lesson teaching, subtly guides the student to form the correct ideas, realize their own values. Second, the richness of the contents. The ideological and political curriculum resources are not limited to the textbooks, classroom teaching and the schools; the whole society contains the potential curriculum resources, including teachers, students' life experience and social practice, etc. All can be used for classroom teaching, and can be used as the ideological and political lessons curriculum resources. Effective use of these resources in the process of teaching can make classroom teaching more vibrant. Third, the openness of materials. Range of time and space is open, such as textbooks, teaching material, classroom teaching, network and society, etc. The subject of resource utilization is open. Not only ideological and political education experts and scholars, political teachers and also students can do social practice to explore the development and utilization of curriculum resources.

\section{The development and utilization of ideological and political lesson curriculum resources}

The development and utilization of Content-based curriculum resources development and utilization is not rich enough. Content-based curriculum resources refer to the consolidation according to the actual teaching situation, the choice of material sources and the exits of its corresponding conditional resources. Knowledge, skills, experience, activity way and method, emotional attitude and values and training target belongs to content-based curriculum resources. Teaching material is the most common material resources. Teachers focus on teaching materials and ignored the teaching materials to teach. At the same time, experience, activity way, emotional attitude material curriculum resources are neglected.

The exits of content-based curriculum resources waste have these reasons: first, the teacher did not fully understand the new curriculum concept. Teachers change the way of traditional teaching and the way of thinking also needs a period of time. Teachers' consciousness is weak and failed to fully understand the role of subjectivity and students. Second, teachers' teaching tasks are too heavy. Each semester and each teacher has a lot of teaching tasks, they have to prepare large amount of information and change speed, it is difficult to have sufficient time to collect materials related to teaching, and it caused they explain the book only. Third, the teachers' abilities. The development of modern information technology brings convenience to the content-based curriculum resources, these materials need to be improved and combine with students' life and practice, and this requires teachers to improve their own quality and ability.

Course resources development makes teachers become students' guiders and developers of using course. In the process of development and utilization of curriculum resources will urge teachers to 
obtain knowledge, strengthening cooperation with other teachers in order to improve capacity to implement development and utilization of curriculum resources. Inquiry and collaboration are two modern basic ways for teachers to upgrade their professional skills. Study on exploitation and utilization of curriculum resources can really reflect student learning subject and make closer to ideological content and establish more contact to enrich students ' life experience and enhance the students' perceptual knowledge. In the past ideology and politics too much focus on imparting basic knowledge and cling to the students with basic theories, ignore students ' attitudes.

The hidden curriculum resources development and utilization has a low proportion. The hidden curriculum resources are compatible with dominant curriculum resources. It is a kind of potential and imperceptible resource. The school environment, class atmosphere, teachers' behavior and the relationship between teachers and students are all hidden curriculum resources. This kind of recessive resources regulating the behavior of the students, in the form of potential and affects the student's thought and behavior. In the classroom teachings, teachers often ignore the hidden curriculum resources development and utilization, result the decline in the students' interest in learning and teaching is difficult to achieve our goals.

The reasons of hidden curriculum resources waste: first, many teachers lack clear understandings of hidden curriculum resources. Cognitive deviation will cause waste of recessive course in classroom teaching resources. Second, classroom teaching is too theoretical sermon, ignore with the combination of social life. Saw and heard of the teachers will cause students thought about some meaningful questions, such facts in our life affect student far more than theoretical sermon. Third, the development of hidden curriculum resources and the limitation of examination oriented education. Exam-oriented education for the purpose of the test, limit the initiative of the students. Students passively accept teachers' giving boring theory knowledge, and at the same time, hidden curriculum resources development and utilization are neglected.

Outside the school curriculum resources development and utilization of inadequate. Outside the school curriculum resources is relative to the existence of the school curriculum resources. It in the contents of includes external libraries and museums and memorial halls and local course resources, etc. Outside the school curriculum resources waste because: first, the school provides insufficient material resources. Schools with limited funds and equipment cannot provide teachers and students visit our field conditions, such as school curriculum resources development and utilization of the limited. Second, the teacher Shared outside the school curriculum resources consciousness is not strong. Teachers should make full use of the library and network resources sharing, so that to improve the classroom teaching. Third, still need to improve students' initiative and enthusiasm. Students as the main body of classroom teaching, we should actively participate in social practice experience, to combine theory with practice better.

\section{To solve the problems of the ideological and political curriculum resources development and utilization of several ways}

Flexible curriculum resources development and utilization of material. The curriculum resources' development and utilization of ideological and political is flexible material. Only economic and political and social life culture phenomenon such as flexibility in teaching, combined with theoretical knowledge is very good, to make students better understand and accept the knowledge independently. And then improve the ability to participate in social life, increase the experience of social practice. School is the main place to course activity, is also the course resources 
focus on the highest density. Schools in order to meet the requirement of the curriculum standard have realized training goal, therefore always positive development and utilization of curriculum resources. Therefore, to the development and utilization of ideological and political lesson curriculum resources, must give full play to the role of the school the main body. On the one hand, schools should actively develop curriculum resources. On the other hand, Schools for teachers and students, on the other hand, the development and utilization of curriculum resources to provide the necessary protection.

Agile development and utilization of resources should pay attention to situation teaching material. Ideological and political lesson teacher should actively create story situation and the question situation and situation of cooperation, the students study and life in contact with the story to the situation, make students easily master the knowledge, skills, in the situation

Adjust the hidden curriculum resources development and utilization of the proportion. The ideological and political course resources development and utilization appropriately increase the proportion of hidden curriculum resources. Hidden curriculum's resources are regulating the behavior of the students in the teaching activities. It is in the rich and colorful life; make the ideological and political education extension to the practice. Hidden curriculum resources development and utilization from the classroom lectures, practice the theory of Dewey's "education is life". Teachers are in the teaching for guidance and inspiration. Transfer of knowledge in the teaching environment and atmosphere, input of education information, potentially, undertake to the student ideological and political education.

Should schools through a variety of ways and methods, for example, with parents and the community as well as other related department to establish close contact, forming longitudinal from the grassroots to school to the local administrative department of education and scientific research departments at all levels and curriculum research center, lateral from inside the education to the education connected to external crisscross network of curriculum resource development to form the overall effect of curriculum resources development and advantage. At the same time, the real curriculum resources sharing also must establish the corresponding experience exchanges and cooperation mechanism regularly carry out teaching experience exchange and school-running ideas for discussion and other activities.

Outside the school curriculum resources complementary functions into full play. Outside the school curriculum resources is the extension of the school curriculum resources, in according to the curriculum standard of resources development and utilization of the school at the same time, play to enhance the teaching effect of course resources complementary role. Only in this way can we in a variety of activities, is advantageous to the teaching curriculum resources and improve the students' creativity, in order to develop students' horizons and enhance the teaching effect.

Schools according to the actual situation and the specific needs of student development, extensive use of libraries and museums and outside forces and government agencies and enterprises and institutions of higher learning and scientific research institutes and other social resources and rich in natural resources. Actively use and development of curriculum resources, play a variety of public network resources effectively. Schools in rural areas can also according to the rural construction and development of the actual development of a variety of unique curriculum resources. Governments at all levels and the administrative department of education has the responsibility to strengthen management, establish and improve the curriculum resources of face-to-face on the policy 
transformation mechanism, strengthening these connections between various kinds of curriculum resources and sharing.

First of all, make full use of external human resources, invite professional report. Outside experts and scholars and excellent front-line teachers in teaching of ideological and political education has its own unique insights and rich practical experience, and invited them to a lecture, face-to-face communication with students, not only can promote the students understand the knowledge, also can develop the students' field of vision.

Second, let the students into the society, to experience life in a particular context. Such as museums and memorial halls, etc. Teachers can lead students to the various job fairs, experience the recruitment conditions and processes, so as to help students to establish correct greatly. Teachers can lead students to visit the national art gallery, causes the student to experience the rich heritage of the Chinese culture, understanding of "the more national, the more the world" of the profound connotation. Therefore, the teacher in making full use of library and the school curriculum resources at the same time, to give full play to the complementary role of school curriculum resources. Make the fullest use of these resources, will expand the students' learning space, and promote the students' physical and mental development better.

Ideological and political lesson needs to have enough curriculum resource as support, without curriculum resources support, the ideological and political lesson classroom will lose vitality, become a hollow moralizing and mechanical knowledge. Therefore, the research ideological and political lesson curriculum resources development and utilization, on the one hand, can enrich the theory of curriculum resources. On the other hand can provide theory support for the practice of the development and utilization of curriculum resources, in order to meet the needs of a line of teaching, finally promote the development of curriculum reform. Big background, this article in the new curriculum reform based on the domestic scholars on the research on the development and utilization of curriculum resources, combined with my participation during the education internship experience, try for the high school ideological and political lesson curriculum resources development and utilization in the analysis of existing problems, combining the characteristics of the inherent in the ideological and political lesson curriculum resources, boldly put forward the curriculum resources development and utilization process should follow the principle of, finally it is concluded that the ideological and political lesson curriculum resources development and utilization ways and methods.

\section{References}

[1] Wu Song nian: Effective teaching art[M]Beijing: education science press, 2008

[2] Wu Gang ping: theory curriculum resources [J]education and research, 2009 (9) 